\title{
HBIM FOR CONSERVATION AND MANAGEMENT OF BUILT HERITAGE: TOWARDS A LIBRARY OF VAULTS AND WOODEN BEAN FLOORS
}

\author{
D. Oreni ${ }^{a}$, R. Brumana ${ }^{a}$, A. Georgopoulos ${ }^{\text {b }}$, B. Cuca ${ }^{\text {a c }}$ \\ ${ }^{a}$ Politecnico di Milano, Milano, Italy - (raffaella.brumana, daniela.oreni, branka.cuca)@polimi.it \\ ${ }^{\mathrm{b}}$ Laboratory of Photogrammetry, School of Rural \& Surveying Engineering, National Technical University of Athens, Greece \\ drag@central.ntua.gr \\ ${ }^{c}$ Cyprus University of Technology, Limassol, Cyprus
}

\begin{abstract}
KEY WORDS: 3D content model, HBIM, laser scanner, geospatial data, built heritage, geometric analysis, survey interpretation, conservation, management
\end{abstract}

\begin{abstract}
:
The paper illustrates the utility to switch from a 3D content model to a Historic Building Information Modelling (HBIM) in order to support conservation and management of built heritage. This three dimensional solution is based on simplified parametric models, suitable for industrial elements and modern architecture, that can be usefully applied to heritage documentation and management of the data on conservation practices. In this sense, the potentials in starting the definition of an HBIM targeted library are investigated, towards the logic of object data definition, beginning from surface surveying and representation. In order to motivate the opportunity in using this 3D object modelling instruments, some case studies are investigated in the paper. Vault and wooden bean floor analysis show how a HBIM for architectural heritage could be implemented in order to assemble different kind of data on historical buildings, such as e.g. dimensional, geometrical, thematic, historical and architectural information.
\end{abstract}

\section{INTRODUCTION}

Conservation of built heritage is progressively linked to the regular maintenance of buildings, defining the preventing conservation as a real necessity in everyday practice. In this view, it is necessary to have an instrument that allows to collect, compare, share and manage all the data available concerning the geometry and state of conservation of buildings. Such data include, among others, products of surveys, drawings, thematic and historical contents, but the information about maintenance or restoration activities should also be added. This paper discusses the possibility to advance from 3D content models to a Historic Building Information Models (HBIM) in order to support preventive conservation, information sharing and knowledge dissemination of heritage for professionals, public institutions and experts involved in the decision making process. Paragraphs 2.1 and 2.2 describe in detail three-dimensional content models, while paragraph 2.3 gives a brief overview on the use of HBIM for built heritage, at Italian and European level, analysing the questions of data sharing, interoperability and standards in using different software. Some case studies, section 3, illustrate the use of BIM solution for the documentation and management of architectural heritage.

\section{FROM 3D CONTENT MODELS TO HBIM FOR BUILT HERITAGE}

Surveying of historical buildings and its elements requires methods of data collection and representation able to describe buildings in a detailed manner, without arbitrarily selecting information (The Getty Conservation Institute, 2007). Survey products, or better geometric documentations, represent an important instrument of knowledge and support for thematic analysis and diagnostic investigation, essential for the maintenance program and the project of conservation of the building (Della Torre, 2003). Moreover, assessment and documentation of historic buildings require a constant integration between geometrical analysis, structural observation, decay investigation, social and economic analysis (Stylianidis et al., 2011)

\subsection{D data acquisition}

Technological progress in recent years, especially in the fields of computer vision and laser scanning, have made the collection of three dimensional information about the world and the objects around us a possibility. Geomatic engineers have now the means to reliably acquire and determine the position of millions of points on the surfaces of interest. This data acquisition may be accomplished in two main ways: either thorough (1) non image based or (2) image based methods.

Sophisticated laser technology is employed for the wealth of terrestrial laser scanning instrumentation available, such as time-of-flight or phase shift or triangulation or structured light systems. On the other hand, structure-from-motion (SfM) algorithms and powerful computers are combined in order to extract three dimensional information and texture from an image sequence (Vaiopoulos et al., 2012, Nex et al., 2008).

In this context the richness of data acquired should be treated with caution, as reliability and accuracy vary a lot and are affected by the environmental conditions, the instrumentation used, the object itself and, of course, the experience of the operator. In addition, and in the case of image based methods, qualitative information is also recorded through the digital images. This is a very important fact for the possible processing within a HBIM later.

Availability of 3D data usually enhances the production of 3D models. Geometrical representations and 3D models must support systematic readings of all the metrical, structural and material aspects that characterize the various parts of the building, and must enable the collection and storing of other useful contributions to completely describe the architecture: Terrestrial Laser Scanner surveys and related modelling software are progressively improving the possibilities for 3D model generations; high resolution 3D texturing models 
obtained from complex object image block, metric and photographic surveys, are devoted to support co-related information, such as archival, historical data, stratigraphic data, pathologies of degradation, crack's investigations and the results of diagnostic and instrumental analysis. On the other hand geometrical models must allow a continuous transition in scale between the survey of the whole architectural complex and its elements, enabling to cross data at different levels of detail and to support the next phases of information and reading interpretation.

The contribution of this kind of representation method does not end in a better organization and description of data survey, but it provides an important support for the planning and implementation of maintenance and conservation projects. Furthermore, it allows the control of the interactions between the various technology components of the building. In addition, a useful model could promote an easy, open and integrated circulation and use of data collected, by all those who in different ways are called to work on the existing building.

\subsection{D content models}

The elaboration of accurate and realistic 3D content models of historic buildings is strictly related to the requirements regarding the intervention planned. In order to be really useful to the professionals in the field, the model should not only be a 3D surface model, but it must take into account the geometric laws of construction, the thickness of the walls, the materials, the organisation of elements and the different construction periods of every part of the structure (Brumana et al., 2013). The investigation of the existing buildings and their constructive techniques starts from the observation of the existing parts, moving gradually through suitable surveys towards the virtual reconstruction of the historic structures. This approach aims to generate a dynamic interpretative model, to define control alarm thresholds and to identify the sources of risk in respect to the structural and environmental stresses, in order to support analysis, simulations and retroactive control (Oreni et al., 2012). Consequently 3D content models can be integrated to traditional two dimensional representations, i.e. conventional drawings, of the built heritage.

The limit in using this kind of models in maintenance and conservation activities consists in the necessity to manually connect the shape of the elements with thematic information collected in databases. Consequently, morphological representation of the surveyed surfaces belonging to complex elements, such as facades, vault systems, domes and slabs, request to be integrated within the logic of object model generation (Brumana et al., 2012).

\subsection{HBIM for management and conservation}

HBIM is a recent solution for three-dimensional parametric representation, which enables the user to draw models and manage data on historic architectural elements, within a common software environment (Cooperative Research Centre for Construction Innovation, 2009). In particular, this tool allows to combine content information on buildings with data derived from the use of survey technologies (i.e. laser-scanner point clouds, 3D models, digital orthophoto, monitoring data), in order to obtain a 3D model in the form of a geo-referenced spatial information structure (Pauwels et al., 2008).

The definition of BIM, as "modelling of both graphical and non- graphical aspect of the entire Building Life cycle in a federated database management system" (CBentley), underlines the strict relation between object modelling and information involving different aspects, devoted to the maintenance process of a building. Born with the aim to manage the US marine real estate buildings, BIM software were initially used to manage new building constructions (Lee et al., 2006. Eastman, et al., 2008). Today they represent an opportunity for heritage documentation and conservation management but they still require a methodological discussion and practise experimentation in order to obtain detailed models of irregular historical objects, that will be really useful for their preservation and maintenance activities.

Parametric models are related to data collected in a database and every change of a parameter causes a change in the shape of the elements (Boeykens, 2011. Boeykens et al., 2012); but, at the moment, a shared library for historical elements does not exist. The necessity of the libraries' implementation requires the development of methodologies and algorithms to use data survey, especially point clouds, and to model in BIM software (Murphy et al., 2013. Dore et al., 2013. Chevrier et al., 2010), avoiding the oversimplification of the shapes. As a consequence, it is essential to think about the level of detail and simplification of the models useful for conservation projects, related to the real possibility to modify the parameters of the shape of the architectonic elements, in particular, of historical object that are often irregular, in an isotropic manner. In this context it should be stressed that so far no standards and specifications have been proposed for the introduction into BIM environment of realistic 3D models, that could incorporate all the possible deviations of an element from its ideal model, due to the construction.

The literature concerning HBIM illustrates how a library of interactive parametric objects can be constructed (Tang et al., 2011), principally starting from historical dimension given by architectural pattern books (Fai et al., 2011). According to this aim, the individuation of shape grammar and stylistic rules can be used to build a first library of historical elements of built heritage. Different kind of architectonic manuals are used to obtain dimensions, proportions and information on geometrical construction (Dore et al., 2013).

One of the aims of this research is to focus the attention on the construction of libraries of architectural elements starting from their survey, using not only laser scanner data (Leica HDS6000, Faro Focus 3D CAM2) but also measurements surveyed with traditional instruments. This solution allows both (1) to build an abacus of local constructive elements and (2) to compare the real dimensions of the elements with the information derived from architectural pattern books. The aim of this process is to describe models in detail according to the specific situations.

\section{HBIM: SURVEYING INSTRUMENTS AND 3D MODELLING METHODOLOGY. TOWARD AN ONTOLOGIC DATABASE}

Here few case studies are considered regarding the construction of HBIM applied to structural systems of historic buildings widely used in north of Italy to cover the spaces of traditional architecture: in particular historic wooden bean floors, brick vaults and wooden vaults.

The survey of many of such structural elements, grouped for typologies, geometries and age of construction, showed a lot of significant differences in the textures, the dimensions of the elements, the whole shape and the materials. Consequently the necessity arises to use HBIM to model these structures, starting from the real dimensions, into the direction of valorisation of the differences, depending from local traditional constructive technologies. In a logic of BIM construction for conservation, it is however necessary to find a compromise in modelling in 
order to create a shared library of those kind of elements, which general drawings could derive from historical architectural pattern. This is a kind of approach that asks a continuous change of scale, from general to detail, in a progressive elaboration of knowledge and management of built heritage.

The methodology followed for the HBIM construction of the structural covering systems, starting from laser scanner surveying and orthoimage generation, can be summarized in the following steps:

1) Definition of the macro-families "component” of structural elements: i.e. slab, brick vault, wooden vault;

2) Definition of hierarchical aggregation of different object elements composing the object family: a) structural, b) nonstructural elements, and c) decorative layers;

3) Definition of the material of each object element.

In the case of wooden bean floors, following elements have been defined: the structural layers made by the principle beans and by the secondary beans, the non-structural elements, such as floorboards, and the decorations, using the stratigraphy definition, such as the plaster and painted layers, the stuccos and so on. In the case of vault system, are defined the structural layers made of: brick block texturing, the ties, the provisional centring wooden ribs, the plasters and stucco stratigraphy.

The definition of such hierarchies of objects is the starting point for the definition of a database of structural elements finalized to the construction of HBIMs, that take into account the state of conservation of the surveyed structures and the integrated information on geometry and construction technologies. Libraries of parametric object definition, coming from the manuals and guides on the historic construction technologies, can be joined to build up a diachronic repository of the different solutions and variations in respect to the chrono-types along a temporal range and across regional areas, showing the permanencies and mutations surveyed on site.

\subsection{Data sharing and interoperability: Data Dictionary, IFD and IFC for HBIM}

When speaking of heritage preservation and maintenance it is pretty hard to refer to a single methodology for recording and documentation practice: survey of a site or a building requires a correct documentation and data organisation in order to obtain a Spatial Data Infrastructure (SDI), adequate for all communities dealing with heritage. In addition, the European scientific community stresses upon the need of Metadata for Architecture Context (MACE Project, 2008) and it defines concepts of "traditional content metadata and ontologies, context metadata, usage related metadata and metadata acquired though social interaction", in the direction also of the fragmentation, reliability and longevity of the data (Addison et al., 2008).

The International Framework for Dictionaries (IFD) is a mechanism that allows the creation of multilingual dictionaries or ontologies. The Data Dictionary is one of the core components of the buildingSMART technology. The dictionary, named IFD Library, is a reference library intended to support improved interoperability in the building and construction industry. IFD Library provides a flexible and robust method of linking existing databases with construction information to a buildingSMART based BIM.

Given that the IFD defined inside the BIM software are not exhaustive for the Historical Building domain, the definition of dictionaries inside the Historical Building Framework (H-IFD) aims to contribute in creating an open DB, updatable, dynamically adaptive to the real context and multi-faced contents of the historical architectures.
Once progressively defined HBIM object libraries, such as the one following described and others under development (Murphy et al., 2013), Informative System developed to support the Planned COnservation Processes, such as SIRCOP (Della Torre, 2003) could be implemented and integrated within the $\mathrm{H}$ IFD libraries in order to share common vocabularies.

With the aim of ensure a full exploitation, the definition of such libraries need to provide high level of interoperability between different BIM platforms. To this aim buildingSMART open platform, has developed a common data schema that "makes possible to hold and exchange data between different proprietary software applications. The data schema comprises information covering the many disciplines that contribute to a building throughout its lifecycle: from conception, through design, construction and operation to refurbishment or demolition”. Industry Foundation Classes, IFC, are the main buildingSMART data model standard. The IFC open format is registered by ISO as ISO/PAS 16739 and is in the process of becoming an official International Standard ISO/IS 16739.

\begin{tabular}{|c|c|c|c|c|}
\hline \multicolumn{2}{|c|}{$\begin{array}{c}\text { COMPONENT } \\
\text { Covering system: structural } \\
\text { typology }\end{array}$} & \multirow{2}{*}{$\begin{array}{l}\text { Historical } \\
\text { Building } \\
\text { Palazzo } \\
\text { Soldi } \\
\text { Palazzo } \\
\text { Soldi } \\
\text { Villa Reale } \\
\end{array}$} & \multirow{2}{*}{$\begin{array}{l}\begin{array}{l}\text { Territorial Area } \\
\text { (NUTS3) }\end{array} \\
\text { Cremona, } \\
\text { Lombardy Region } \\
\text { (RL) } \\
\text { Cremona, RL } \\
\text { Monza, RL } \\
\end{array}$} & \multirow{2}{*}{$\begin{array}{l}\begin{array}{l}\text { Age of } \\
\text { construction }\end{array} \\
\mathrm{XV} \text { cen. } \\
\mathrm{XVII-XVIII} \\
\text { cen. } \\
\mathrm{XVIII} \text { cen. } \\
\end{array}$} \\
\hline $\begin{array}{l}\text { Wooden slabs } \\
\text { brick vaults } \\
\text { system }\end{array}$ & $\begin{array}{l}\text { Wooden } \\
\text { slabs } \\
\text { pavillion } \\
\text { vault }\end{array}$ & & & \\
\hline \multirow[t]{2}{*}{$\begin{array}{l}\text { Wooden vaults } \\
\text { system }\end{array}$} & $\begin{array}{l}\text { Pavillion } \\
\text { vault }\end{array}$ & $\begin{array}{l}\text { Palazzo } \\
\text { Soldi }\end{array}$ & Cremona, RL & $\begin{array}{l}\mathrm{XVII-XVIII} \\
\text { cen. }\end{array}$ \\
\hline & Barrel vault & Villa Reale & Monza, RL & XVIII cen. \\
\hline \multirow[t]{3}{*}{$\begin{array}{l}\begin{array}{l}\text { Structural } \\
\text { sequences }\end{array} \\
\end{array}$} & XIV cen. & $\mathrm{XV}$ cen. & XVII-XVIII cen. & $\begin{array}{l}\text { XVIII } \\
\text { cen. }\end{array}$ \\
\hline & $\begin{array}{l}\text { Wooden } \\
\text { slabs }\end{array}$ & $\begin{array}{l}\text { Wooden } \\
\text { Slabs }\end{array}$ & $\begin{array}{l}\text { Brick Pavillion } \\
\text { vault }\end{array}$ & $\begin{array}{l}\text { Brick } \\
\text { Pavillion } \\
\text { vault }\end{array}$ \\
\hline & & & $\begin{array}{l}\text { Wooden Vaults } \\
\text { system }\end{array}$ & $\begin{array}{l}\text { Wooden } \\
\text { vaults }\end{array}$ \\
\hline
\end{tabular}

Table 1. (Up) Syncronic territorial structural solutions of the built heritage analyzed. (Down) Diacronic sequences of the structural elements.

\section{HBIM OF TRADITIONAL COVERING SYSTEMS: TOWARD A LIBRARY OF HISTORIC ELEMENTS}

For the research here presented, two different BIM software platforms have been compared, (C)Autodesk Revit and (C) GraphiSoft ArchiCAD, concerning the possibility to model irregular objects that constitute covering structural elements in architecture. Point Tools (@Bentley) plug in for point clouds modelling, within (CRhino modeller and CLeica tool for Revit has been tested in order to construct the object families starting from laser scans data. The Interoperability with (CArchiCAD16 is on course of testing in order to define each Room/Zone and to reconstruct the spatial aggregation between the single object components (i.e. walls/façade object, inner walls, slabs).

Comparing the different software for BIM, actual version of ArchiCAD provides greater flexibility and adaptability in the modelling of irregular objects, avoiding operations of model simplification too far from the real shape of the objects.

Space Boundaries relational object will allow the single room unit to be related once to the other inside the whole building construction. Test of interoperability between the IFC output format file are on course of developing with software devoted to the thermal assessment and evaluation based on object room component analysis (VE tools). Export tests of the geometry was aimed to verify the complete interoperability between the different software using gbXML or IFC format file. 


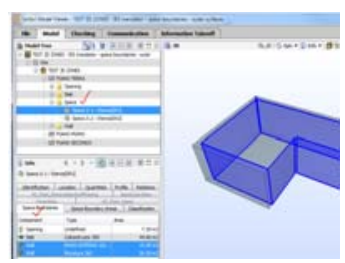

Fig. 2. Space Boundaries definition and aggregation of the single components (wall and slabs) of each room within the building. IFC format is exported to allow interoperability with others tools. Here VE tool for building's thermal evaluation.

\subsection{HBIM of brick vaults}

The construction of the 3D models of vaults and their brick elements requires a deep geometrical analysis and interpretation of the shapes in order to reproduce them virtually with BIM software and to add geometric and constructive content to tridimensional model, in particular on ancient construction technologies and their setting up. In this case the chain between the historical analysis of the construction typologies of the vault systems and the real assessment of each element need to be punctually considered, and it requests a high attention of a systematic analysis to verify the hypnotized structures, using historic architectonic manuals. According to this aim, HBIM guarantees the necessary flexibility that often characterized the time-delayed and progressive phases of diagnostic analysis on built heritage trough the possibility to change the parameters in function of future new investigation. Different geometric typologies of vaults were analysed in order to implement a local abacus of structures and to test the capabilities of the software in managing different information that is possible to add to the elements. Some examples of libraries construction, starting from data surveying, illustrated as following.

- Rib vaults cover the four principal and secondary exedras of the complex of the "Rotonda of Besana" (1713-1725), once a church and cemetery of the "Ospedale Maggiore" of Milan, dedicated to Saint Michele. Apparently they seemed related to a simple spherical implant, cut by the inscribed trapezium, as usually represented on the related historical documents; however, the analysis of the horizontal, transversal diagonal and longitudinal slices extracted from the point clouds have shown a complex ovoid shape, with different directions of the brick block disposition along the same constructive ring (Fig.3). The HBIM of the vaults have been generated on the hypothesis of the most probable brick block texture respect to the geometric shape obtained from the laser scans, because of the impossibility to access to the extrados.

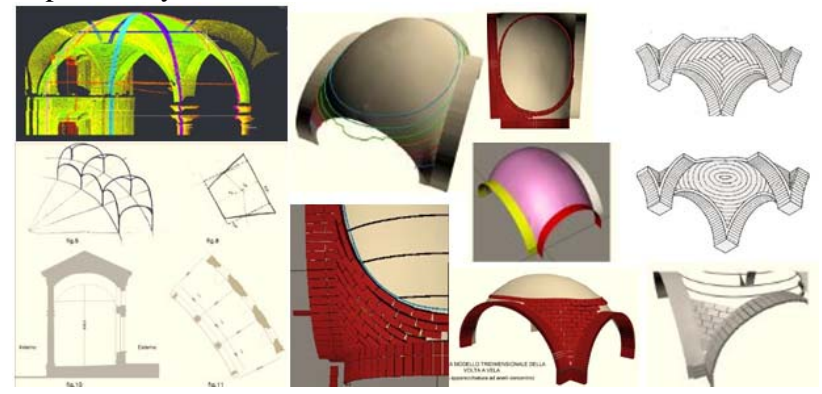

Figure 3. In the methodological path is reconstructed the geometry of the vault inscribed within the trapezium and the result of an ovoid non spherical shape. The 3D HBIM was generated from laser scanner vertical and horizontal slices, and the hypothesized texture of the brick block (CGraphiSoft ArchiCAD). Historic architectonic pattern were used to deduce information on the ideal textures and to compare it with the real geometry of the vault.

- Church of Saint Maria in Scaria d'Intelvi (Como - Italy) has a complex constructive history and its structures were expanded and transformed in decoration more times along the centuries. The high resolution laser scanner survey allowed to model the three vaults that cover the ceiling of the church and to deduce some important information on different stratigraphic phases of construction and on historical use of the centrings. Previous surveys and first observations of the two vaults of the nave suggested they had a unique similar shape and geometry. However, the intention to build a precise $3 \mathrm{D}$ model obliged surveyors to investigate in detail the real geometry of the vaults, extracting from point clouds different sections at different horizontal and vertical levels.

In particular, the modelling of the vaults had to face the irregularity of the geometry: a geometrical simplification to regular forms and the modelling with automated commands hasn't given a satisfying result. Firstly, working with the point clouds, has been necessary to clean the geometry of the vaults from the decoration apparatus, to obtain sections with which to create a mesh. Over it have been arranged the bricks, modeled in its own family, with the aim to study the herringbone patter. The "vault" family, not directly modeled, identifies itself with the "brick" one, that through the parameters can modify its dimensions, allowing, for example, to change easily the thickness of the vault (Fig. 4).

The data survey analysis showed analogies between the irregular shapes of the two vaults, supporting the hypothesis that a single centring was used for both the vaults: after the realization of the first one, it could have been removed, rotated and placed in order to build the second. This could explain the symmetrical disposition of the deformations in the vaults (Fig. 4). In addition, the analysis of the disposition of the bricks from the extrados allowed building a HBIM without supposing any elements but using real dimensions to associate material information.

Three-dimensional model was completed in every part and historical information were associated to each one in order to obtain a HBIM of the whole church and a chronological sequence of the construction phases.

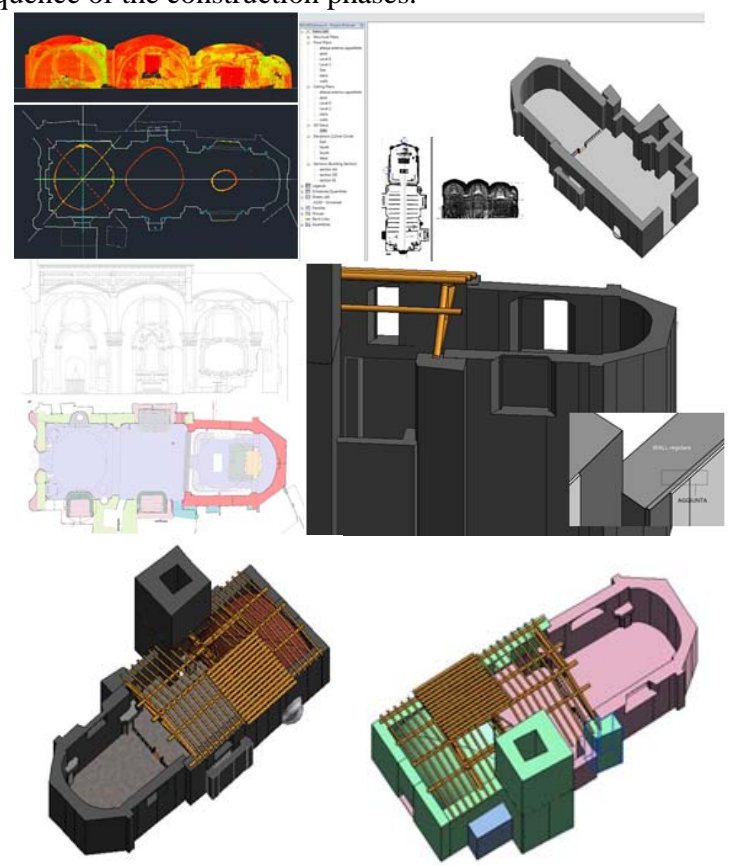


Figure 4. Church of Saint Maria in Scaria d'Intelvi (Como Italy). (Up left) Laser scanner point clouds, transversal section and plan of the church with indication of the different constructive phases derived from the cross-relation of historical

data and surveying data interpretation. The 3D model of the church (down) is made with BIM software (@Autodesk Revit).

\subsection{HBIM of wooden vaults and bean floors}

A similar methodological approach has been applied to the research on wooden vaults, used in the past centuries to cover large rooms and to avoid the transfer of the additional weight on the side walls and on wooden bean floors. Survey and documentation can help both in (1) transmitting skills and structural technology no more in use, and (2) supporting activities of maintenance and conservation.

Similarly to the brick vaults modelling, it was first of all necessary to analyse the interrelation between single elements in order to understand the global behaviour of the structures. Secondly, the intrados and extrados of the vaults and of the floors have been surveyed where possible, in order to measure the elements with laser scanner and hands on techniques. The possibility to insert information about the connection metal or wooden elements between the different part of the structure was fundamental to build a 3D model really useful for conservation plan and management.

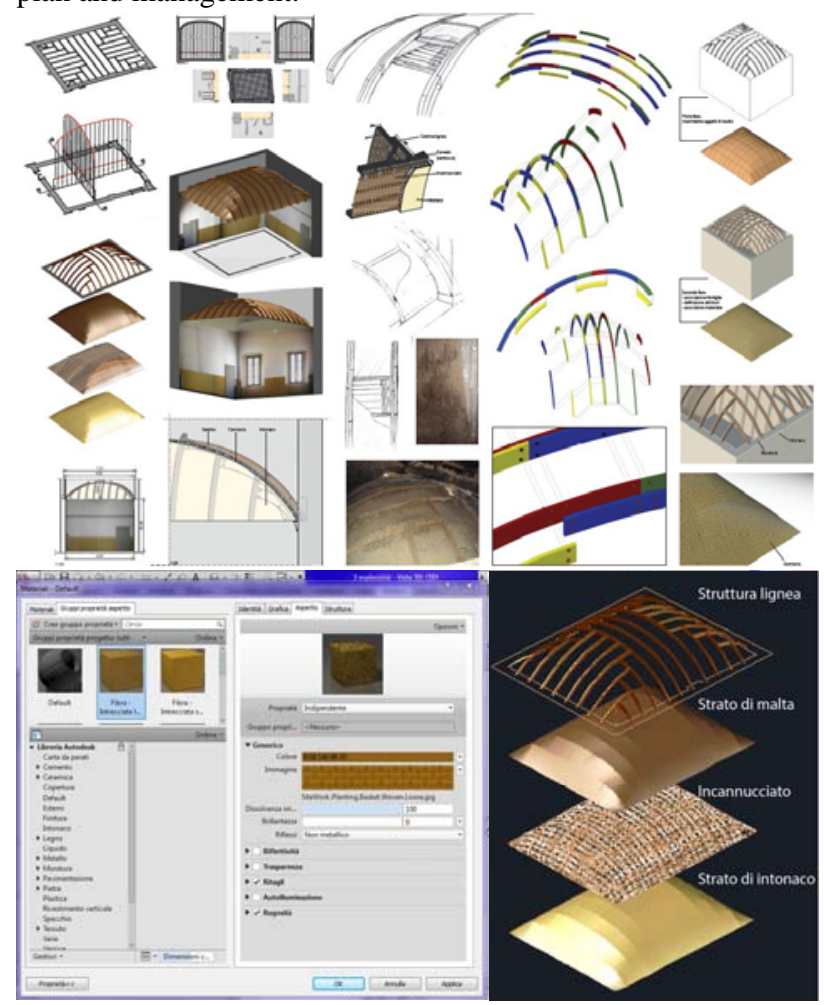

Figure 5. HBIM (@)Autodesk Revit) of wooden vault in Soldi Palace in Cremona (Italy): 3D elements modelling process using laser scanner point clouds and hands on measurements. Information on materials, their stratigraphy and geometrical data of architectural elements are indicated in the database.

The HBIM re-construction of the wooden vaults (Fig. 5) and bean floors (Fig. 6) of Palazzo Soldi in Cremona (Italy), illustrates the importance of stratigraphic analysis of elements used to identify the construction rule of each part in relation with the general structure. Information on different materials, their state of conservation and dimensions were inserted in the database but the issues on implementation of the quantity and quality of data represent at the moment a limit in using BIM for heritage.

\subsection{Conclusions}

HBIM is based on simplified parametric models, suitable for industrial elements and modern architecture, while further investigation should be done in order to apply this kind of documentation in broader heritage conservation practices.

The case studies showed how it could be possible to experiment and verify the transition from the concept of surface towards object representation, supporting enhanced comprehension of the single elements within the model information of the overall building organism, and allow the connection to descriptive thematic database (constructive technologies, elements abacus), in a logic of semantic content models. These kind of threedimensional detailed virtual models are useful instrument for improving remote access to data that could provide support to advanced programs for preventive conservation and guarantee sustainable interventions and maintenance over time. Moreover such 3D models can be able to host both geometrical - historical survey data and materials or degradation information.

HBIM libraries implementation for built heritage elements requires a wide and shared research on drawings, elaboration and interpretation activities of survey data: consequently it is necessary that this aim is shared as much as possible between the expert in documentation and representation of the built heritage. Standards and interoperable IFC and IFD need to be deeper investigated and implemented (Stylianidis et al., 2011). Detailed documentation of architectural heritage should be based on a common vocabulary, taking in account the differences that characterized the heritage and on data gathered with a systematic, unified process, with increasing degrees of details. The aim of this process is, on one hand, to create significant content that is as broad ranging as possible, in line with adequate cognitive standards (not only complying with the parameters of the Italian "ICCD - Istituto Centrale per il Catalogo e la Documentazione", Central Institute for Cataloguing and Documentation); and on the other hand, to develop a fully implemented and interoperable tool to support conservation activities, which can be integrated with the instruments deployed in everyday planning procedures that regards existing buildings.

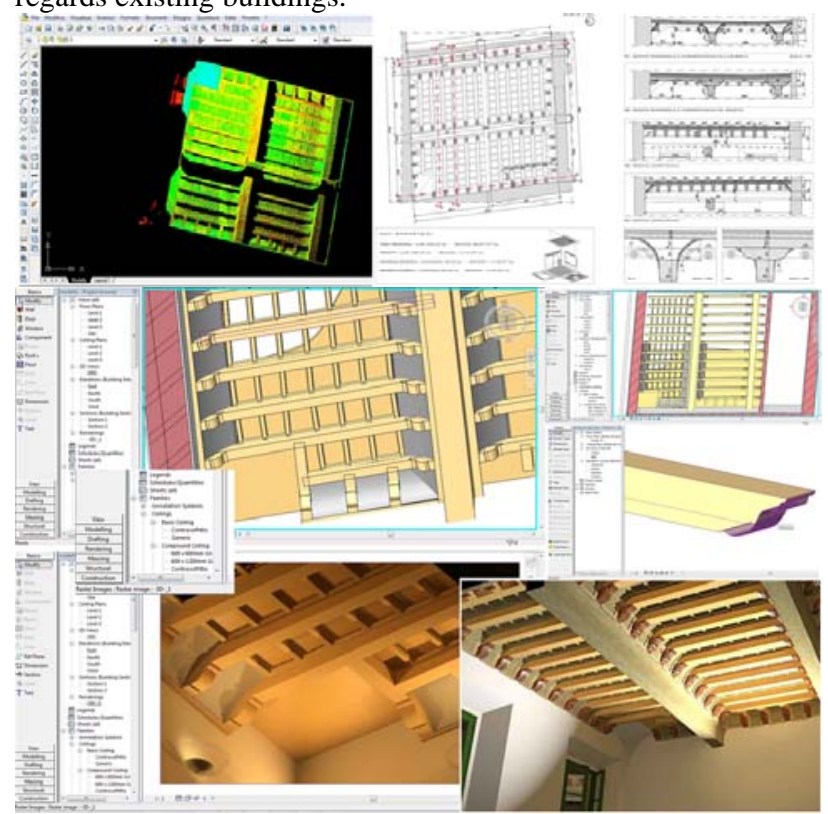


Figure 6. HBIM (@Autodesk Revit) of $15^{\text {th }}$ century wooden roof in Soldi Palace in Cremona (Italy): ceiling family definition and hierarchical components. Laser scanner data and hands on dimensions were integrated to obtain a detailed 3D element model of the historical wooden structures.

\section{ACKNOWLEDGMENTS}

The authors wish to acknowledge Proff. A. Grimoldi and L. Binda for their scientific knowledge of technological and constructive analysis during survey and the Master courses students for testing the methodology in such a didactic path.

\section{REFERENCES AND SELECTED BIBLIOGRAPHY}

\section{References from Journals:}

Brumana, R., Oreni, D., Cuca, B., Binda, L., Condoleo, P., Triggiani, M., 2013. Strategy for integrated surveying techniques finalized to interpretive models in a byzantine church, Mesopotam, Albania. On publishing in International Journal of Architectural Heritage.

Chevrier, C., Charbonneau, N., Grussenmeyer, P., Perrin, J.P., 2010. Parametric documenting of built heritage: 3D virtual reconstruction of architectural details. International Journal of architectural Computing, 8 (2), pp. 131-146.

\section{References from Books:}

Addison, A., Santana Quintero, M., Severo, M., 2008. Cultural heritage repositories: Digital Archives for Conservation and Management. In Browsing architecture: Metadata and Beyond. Fraunhofer IRB, pp. 306-317.

Cooperative Research Centre for Construction Innovation, 2009. National Guidelines for Digital Modelling. Icon.Net Pty Ltd., Brisbane, Australia.

Della Torre, S., 2003. La conservazione programmata del patrimonio storico architettonico. Linee guida per il piano di manutenzione e consuntivo scientifico. Guerini, Milano.

Eastman, C., Teicholz, P., Sacks, R., Liston, K., 2008. BIM Handbook. A guide to Building Information Modeling for Owners, Managers, Designers, Engineers, and Contractors. Jonn Wiley \& Sons, Hoboken, New Jersey.

The Getty Conservation Institute, 2007. Recording, Documentation, and Information Management for the Conservation of Heritage Places. Los Angeles.

Stylianidis, E., Patias, P., Santana Quintero, M., 2011. CIPA Heritage documentation - best practices and applications. CIPA.

\section{References from Other Literature:}

Boeykens, S., 2011. Using 3D Design software, BIM and game engins for architectural historical reconstruction. CAAD Futures, Liege, Belgium, 6-8 July.

Boeykens, S., Himpe, C., Martens, B. 2012. A case study of using BIM in Historical Reconstruction - The Vinohrady synagogue in Prague. 30th International Conference on Education and research in Computing Aided Architectural Design in Europe, Prague, Czech Republic, 12-14 September.
Chevrier, C., Maillard, Y., Perrin, J.P., 2009. A method for the 3D modelling of historic monuments: the case of a gothic abbey. In: The International Archives of Photogrammetry, Remote Sensing and Spatial Information Science, 38 (5/W1), (Cd-rom).

Dore, C., Murphy, M., 2013. Semi-automatic modelling of building facades with shape grammars using historic building information modelling. In: The International Archives of Photogrammetry, Remote Sensing and Spatial Information Science, XL (5/W1) (Cdrom).

Fai, S., Graham, K., Duckworth, T., Wood, N., Attar, R., 2011a. Building Information Modelling and Heritage Documentation. 23rd International Symposium, International Scientific Committee for Documentation of Cultural Heritage (CIPA). Prague, Czech Republic.

Fai, S., Duckworth, T., Graham, K., Wood, N., 2011b. Building Information Modelling and the Conservation of Modern Heritage. The 24rd World Congress of Architecture, Union International des Architects (UIA). Tokyo, Japan.

Lee, G., Sacks, R., Eastman, C.E., 2006. Specifying parametric building object behaviour (BOB) for a building information modelling system. In: Automation in Construction, 15(6), pp. 758-776.

Murphy, M., McGovern, E., Pavia, S., 2013. Historic Building Informatio Modelling - Adding intelligence to laser and image based surveys of European classical architecture. In: The International Archives of Photogrammetry, Remote Sensing and Spatial Information Science, 76, pp. 89-102.

Nex, F., Rinaudo, F., 2008. Multi-image matching: an "old and new" photogrammetric answer to lidar techniques. Proceedings of ISPRS, vol. XXXVII/B5, pp. 621-626.

Oreni, D., Brumana, R., Cuca, B., 2012. Towards a Methodology for 3D Content Models. The Reconstruction of Ancient Vaults for Maintenance and Structural Behaviour in the logic of BIM management. Virtual Systems in the Information Society. NJ, USA, Milan, Italy, 2 - 5 September, pp. 475-482.

Oreni, D., Cuca, B., Brumana, R., 2012. Three dimensional virtual models for better comprehension of architectural heritage construction techniques and its maintenance over time. Progress in Cultural Heritage Preservation - Lecture Notes in Computer Science, Heidelberg London New York, (7616), pp. 533-542.

Pauwels, P., Verstraeten, R., Meyer, R.D., Campenhout, J.V., 2008. Architectural Information Modelling for Virtual Heritage Application, Digital Heritage. Proceedings of the 14th International Conference on Virtual Systems and Multimedia, Archeolingua.

Vaiopoulos, A. D., Georgopoulos, A., Lozios, S.G., 2012. Comparison of 3D representations depicting micro folds: overlapping imagery vs. time-of-flight laser scanner, Proceedings of SPIE, Earth Resources and Environmental Remote Sensing/GIS Applications III. 
Tang, P., Huber, D., Akinci, B., Lipman, R., Lytle, A., 2011. Automatic reconstruction of as-built building information models from laser-scanned point clouds. A review of related techniques. In: Automation in Construction, 19 (7), pp. 829843.

\section{References from websites:}

INSPIRE EU Directive, 2007. Directive 2007/2/EC of the EU Parliament and of the Council (14 March 2007) establishing an Infrastructure for Spatial Information in the EU Community, Official Journal of the European Union, L 108/1(50), 25th April 2007, at: http://eurlex.europa.eu/JOHtml.do?uri=OJ:L:2007:108:SOM:EN:HTML, Last accessed 10 April 2013

NIBS, 2007. National Building Information Modeling Standard: Overview, principles and methodologies, http://www.wbdg.org/pdfs/NBIMSv1_p1.pdfLast accessed 12 April 2013 